\title{
Experimental Research on Residual Stress in the Process of Cemented Carbide Coating Micro Groove Tool Cutting 40CrMnMo
}

\author{
Hong-wan Jiang ${ }^{1}$,Lin $\mathrm{He}^{2,1^{*}}$, Gang Zhan ${ }^{1}$,Zhong-fei Zou ${ }^{1}$ and Jin-xing Wu ${ }^{1}$ \\ 1.College of Mechanical Engineering, Gui zhou University, Guiyang 550025, China; \\ 2.Guizhou Normal College, Guiyang 550018, China
}

\begin{abstract}
Keywords: Cemented Carbide, 40CrMnMo, Residual Stress, Redial Distribution, Experimental Research
\end{abstract}

\begin{abstract}
The cemented carbide coating micro groove turning tool and original turning tool are arranged to cut the same oil country tubular goods (OCTG) 40CrMnMo. By the combination of cutting experiment theoretical analysis, this paper focuses on the radial distribution of residual stress of machined surfaces of the new cemented carbide coating micro groove turning tool through a comparative analysis of the radial distribution of residual stress of machined surfaces from the two turning tool above. Research results show that the micro groove can increase the thickness and the maximum value of residual compressive stress, and reduce the thickness of residual tensile stress and the value of residual tensile stress of surface material of workpiece.
\end{abstract}

\section{Introduction}

Almost all of the machining methods can not obtain a very good machined surface, so a standard to measure the surface quality is necessary. The residual stress of machined surface is a rather important evaluation index, and a lot of research work has been done on the residual stress of machined surface at home and abroad. Sun et al. [1] establish a 3D finite element model to simulate the orthogonal cutting of aviation material aluminum alloy. The influence of various factors on residual stress is obtained. Liu et al. [2] explain the mechanism of production of residual stress from the viewpoint of the establishment of finished surface, and introduced the inspection method and its latest development of residual stress. Tian et al. [3] simulate the cutting process of Ti6Al4V using the 3D oblique cutting finite element model at difference cutting speeds and cutting depth. The results show that the cutting speed has great influence on the residual stress of surface. Peng at al. [4] propose a prestressed cutting method to actively control the residual stress distribution status on the machined surface, and the results show that in certain extent suitable compressive residual stress on machined surface are achieved by utilizing theprestressed cutting method. Meanwhile, procedures of residual stress adjustment after machining can be omitted.Wang et al. [5] study the effects of cyclic hardening law and phase transformation on numerical simulation of residual stresses of $10 \mathrm{Ni} 5 \mathrm{CrMoV}$ ferritic high strength steel, and experimental results have shown that the material exhibits hardening in monotonic loading but softening in cyclic loading. Ahmad et al. [6] explore the WEDM cutting parameters to identify the optimum conditions for contour method residual stress measurements, and validate the corrected contour method results by X-ray diffraction, incremental center hole drilling, and neutron diffraction.Nespor et al. [7]compare the residual stress state after machining Ti-6AI-4V using the complex ball end milling process with the fundamental orthogonal cutting and orthogonal planing processes, and it is shown that results can only be transferred if the deformation morphology of the subsurface is considered, which is defined by the tool kinematics and shape of the workpiece.Cellier et al. [8] observe the effect of cutting conditions on the surface residual stress. The results show that the cutting angles have a great influence on residual stress, and a negative axial rake angle can induce compressive residual stresses. Researches above mostly focus on measurement technology of residual stress, finite element simulation of residual stress in cutting process, residual stress of machined surface of nickel-based superalloy, titanium alloy and aluminium alloy, and the residual stress of machined surface in milling process.Experimental research on the residual stress of machined surface in the process of cemented carbide tool cutting 
40CrMnMo OCTG (oil country tubular goods) is rare. Comparative study of radial distribution of residual stress of machined surfaces from original turning tool and innovative designed turning tool has never seen.

In this paper, cemented carbide coating micro groove turning tool and original turning tool cut the same OCTG 40CrMnMo. Non-contact nondestructive testing method----X ray stress measurement is used to realize the contrast test of the residual stress of machined surface from the two turning tools above. Based on the principle and instrument of electrolytic polishing, this paper focuses on the radial distribution of residual stress of machined surfaces. The mechanism of the influence of innovative designed structure----micro groove of the rake face on the radial distribution of residual stress of machined surfaces is revealed.

\section{Cutting Experiment}

The experiment is carried out on the CW6163C lathe, and an appropriate cutting experimental platform is built as shown in Fig.1. The comparative test is under the same cutting conditions: $\mathrm{v}_{\mathrm{c}}=115 \mathrm{~m} / \mathrm{min}, \mathrm{f}=0.42 \mathrm{~mm} / \mathrm{r}, \mathrm{a}_{\mathrm{p}}=2 \mathrm{~mm}$, and the size of the workpiece is $\phi 100 \times$ $200 \mathrm{~mm}$. The mechanical performance of the tool material and the workpiece material and the geometric angle of the tool are shown in Table1 and Table 2 respectively.

Table 1.Property parameters of material

\begin{tabular}{ccccccc}
\hline Material & $\begin{array}{c}\text { Density } \\
\left(\mathrm{g} / \mathrm{cm}^{3}\right)\end{array}$ & $\begin{array}{c}\text { Tensile } \\
\text { strength }(\mathrm{MPa})\end{array}$ & $\begin{array}{c}\text { Bending } \\
\text { strength }(\mathrm{MPa})\end{array}$ & Hardness & $\begin{array}{c}\text { Poisson's } \\
\text { ratio }\end{array}$ & $\begin{array}{c}\text { Elastic modulus } \\
(\mathrm{GPa})\end{array}$ \\
\hline Tool & 13.8 & 784.5 & $\geq 1180$ & $91.8 \mathrm{HRA}$ & 0.23 & $540-600$ \\
Workpiece & 7.87 & 1080 & $/$ & $30 \mathrm{HRC}$ & 0.28 & 212 \\
\hline
\end{tabular}

Table 2.Geometric angle of the tool

\begin{tabular}{cccccccc}
\hline $\begin{array}{c}\text { Geometric } \\
\text { angle }\end{array}$ & $\begin{array}{c}\text { Tool } \\
\text { angle } \varepsilon_{\mathrm{r}}\end{array}$ & $\begin{array}{c}\text { Rake angle } \\
\gamma_{0}\end{array}$ & $\begin{array}{c}\text { Clearance } \\
\text { angle } \alpha_{0}\end{array}$ & $\begin{array}{c}\text { Main cutting } \\
\text { edge angle } \mathrm{K}_{\mathrm{r}}\end{array}$ & $\begin{array}{c}\text { End cutting } \\
\text { edge angle } \mathrm{K}_{\mathrm{r}}^{\prime}\end{array}$ & $\begin{array}{c}\text { Inclination } \\
\text { angle } \lambda_{\mathrm{s}}\end{array}$ & $\begin{array}{c}\text { Approach } \\
\text { angle } \psi_{r}\end{array}$ \\
\hline Value $\left(^{\circ}\right)$ & 150 & -10 & 7 & 27.5 & 2.5 & 0 & 62.5 \\
\hline
\end{tabular}

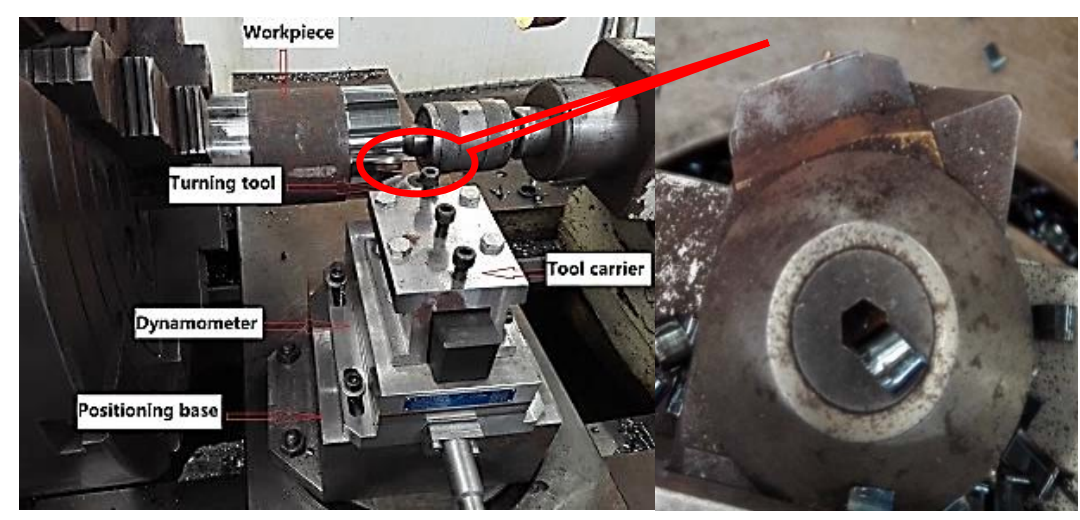

Figure 1. Cutting test platform

\section{Sample Preparation}

Based on the completed test above, the two workpieces machined by cemented carbide coating micro groove turning tool and original turning tool mentioned above is sampled by Electrical discharge machining method. Considering the requirements of the test, the reliability of the data and the reuse of the workpiece and so on, each workpiece is sampled in four symmetrical positionson the circumference. Sampling method, sampling equipment and samples are shown in Fig. 2. 


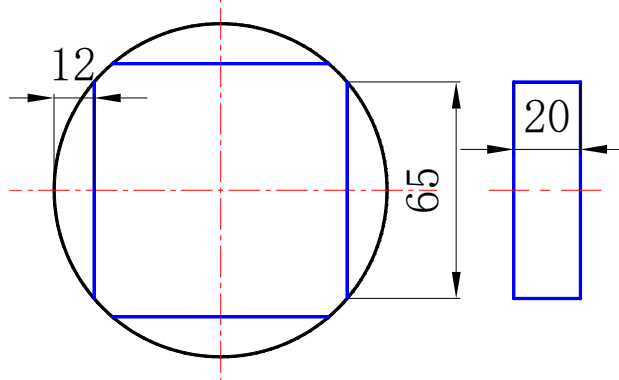

(a)Circumferential sampling

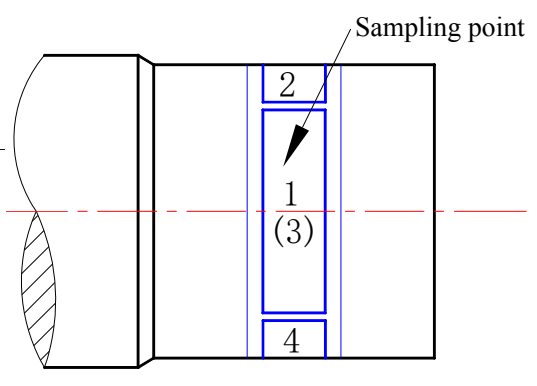

(b)Center sampling

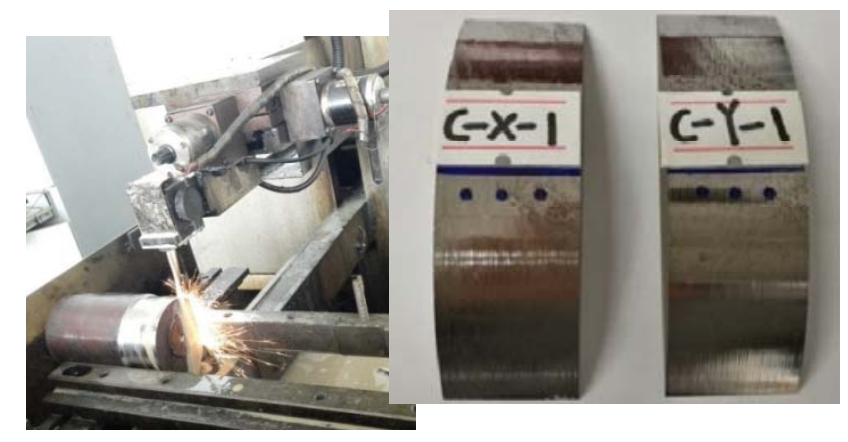

(c) Electrical discharge machining

(d) Samples of workpieces

Figure2.sampling method

After sampling, obtained samples are cleaned and dried. Finally the residual stress of machined surface of the two finished samples can be measured by the equipment as shown in Fig. 3.

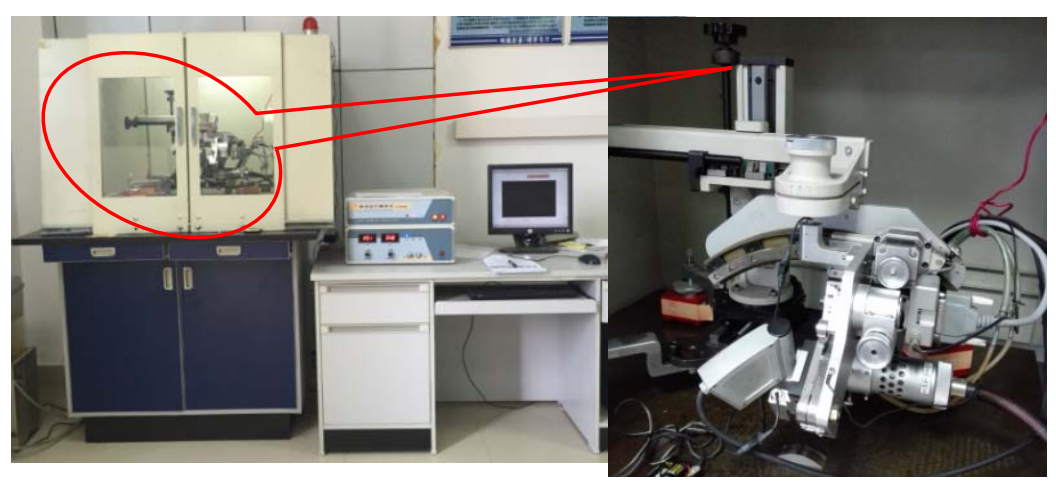

Figure 3. X-ray stress analyzer

According to the thermal and mechanical performance of workpiece 40CrMnMo, related parameters setting are shown in Table 3.

Table 3.Parameters setting of residual stress measurement

\begin{tabular}{ccccccc}
\hline $\begin{array}{c}\text { Measurement } \\
\text { method }\end{array}$ & $\begin{array}{c}\text { Peak } \\
\text { method }\end{array}$ & $\begin{array}{c}\text { Material } \\
\text { type }\end{array}$ & $\begin{array}{c}\text { Scanning range } \\
\text { of } 2 \theta\left(^{\circ}\right)\end{array}$ & $\begin{array}{c}\text { Scanning step } \\
\text { distance of } 2 \theta\left(^{\circ}\right)\end{array}$ & $\begin{array}{c}\text { High pressure } \\
(\mathrm{KV})\end{array}$ & $\begin{array}{c}\text { Electric current } \\
(\mathrm{mA})\end{array}$ \\
\hline Fixed $\psi$ & $\begin{array}{c}\text { Cross } \\
\text { correlation }\end{array}$ & Ferrite & $162 \sim 151$ & 0.1 & 20 & 5 \\
\hline
\end{tabular}

\section{Results and Analysis}

According to sampling and measuringmethod of residual stress of machined surface as shown in Fig. 2, each measurement is repeated 4 times. The average value is seen as the effective data of this 
measurement. Through corresponding measurement and data processing, the measurement results of the residual stress of machined surface of the two turning tool above can obtained as shown in Table 4.

Table 4.Measurement results of residual stress

\begin{tabular}{|c|c|c|c|c|c|}
\hline \multirow{3}{*}{ Measurement } & \multicolumn{5}{|c|}{ Residual stress (MPa) } \\
\cline { 2 - 6 } & 1 & 2 & 3 & 4 & Avarege \\
\hline Original turning tool & 789 & 804 & 795 & 796 & 796 \\
\hline Micro groove turning tool & 631 & 630 & 621 & 627 & 627 \\
\hline
\end{tabular}

According to the metal plasticity forming theory, almost for all metal materials, the greater the compressive stress of machined surface, the better the plasticity of the metal, the stronger the ability to resist the inhomogeneous deformation. On the basis of results shown in Table 4, the residual compressive stress of machined surface from micro groove turning tool is less than the one from original turning tool. So from the viewpoint of surface stress, the plasticity of the surface material of micro groove turning tool is better than the one of original turning tool. In order to explain the problem more powerfully, this paper will make further study on the radial distribution of residual stress of machined surfaces from the two tools above. The machined surfaces of the finished samples are electrolytic polished. And according to physicochemical properties of the workpiece material, based on the electrolysis principle as shown in Eq. (1), proper glycerol is added into saturated salt water to prepare the corresponding electrolyte. The copper is used as the cathode, and the sample is used as anode, and the electrolyticcircuit is formed by supplying $8.2 \mathrm{~V}$ voltage. Layerstripping of the sample is realized by controlling electrolysis time. Electrolyze layer by layer, and measure layer by layer. Ultimately the radial distribution of residual stress of machined surfaces from the two tools above can obtained as shown in Fig. 4.

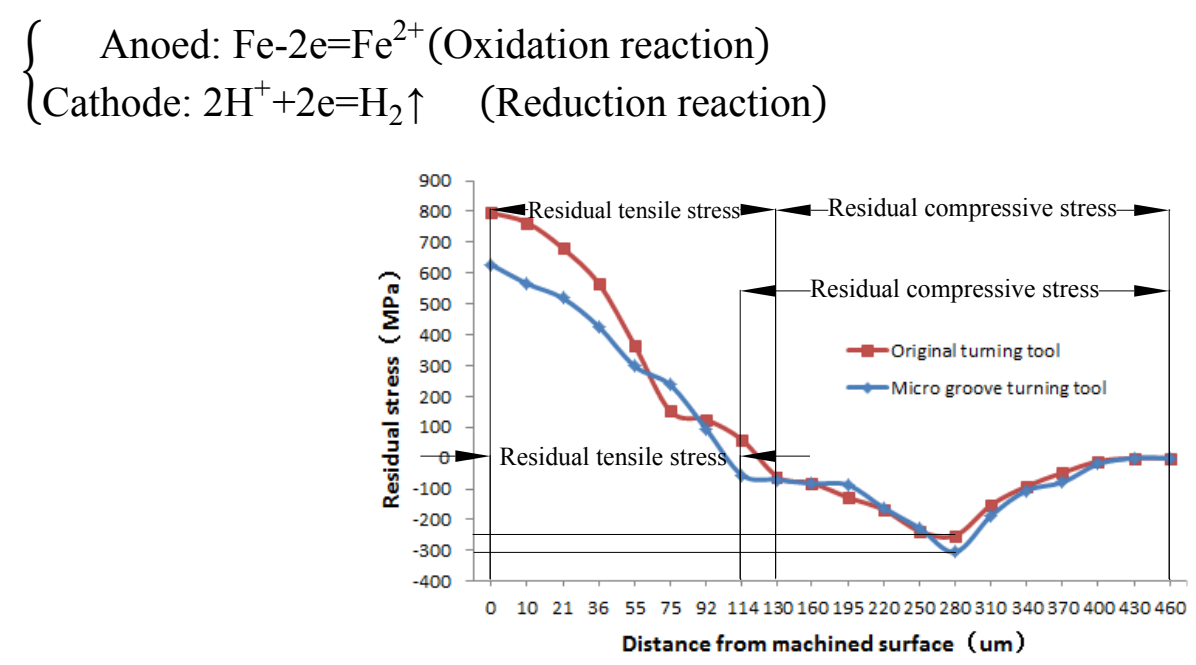

Figure 4.Radial distribution of residual stress of machined surface

The machined surface of workpiece can shrink due to extrusion in the cutting process. Due to the barrier of inner layer material during shrinkage, the surface material is stretched relative to the theoretical shrinkage. Then the residual tensile stress appears in the surface material, and the extensional capacity of the surface material decreases gradually with the increase of depth. So the residual tensile stress decreases. At the same time, the inner layer material can shrink due to the extrusion from surface material. The residual compressive stress appears in the inner layer material. Combined with the experimental results, due to the workpiece material40CrMnMo has been heat-treated to release internal stress before being actually processed in the cutting process. And the internal stress of workpiece material after heat treatment can be considered as eliminated completely. The residual compressive stress in the inner layer material reaches a maximum value, and then increases, and finally approaches zero.It can be seen from Fig. 4 that when the distance 
from the surface is less than or equal to $92 \mathrm{um}$, the machined surface of the two turning tool (cemented carbide coating micro groove turning tool and original turning tool) are all the residual tensile stress, and the residual tensile stress decreases as the radial depth increases. The reduction rate of residual tensile stress of machined surface from original turning tool is relatively larger. When the distance from the surface increases to $114 \mathrm{um}$, the residual compressive stress has appeared on the machined surface from the micro groove turning tool. The stress on the machined surface from the original turning tool is still residual tensile stress. That can illustrate the micro groove can accelerate the coming of residual compressive stress, and reduce the thickness of residual tensile stress. When the measuring depth reaches to $130 \mathrm{um}$, the residual compressive stress just appears on the machined surface from the original surface. The residual compressive stresses of machined surface from the two turning tools increase with the increase of measuring depth. When the measuring depth reaches to 280um, the residual compressive stress of machined surface from micro groove turning tool reaches the maximum value, $304.33 \mathrm{MPa}$. At the same time, the residual compressive stress of machined surface from original turning tool also reaches the maximum value, 251.33MPa. The former is larger than the latter. After that, the residual compressive stresses of machined surface from the two turning tools decrease with the increase of measuring depth. In the position of the depth being about $430 \mathrm{um}$, the residual compressive stresses of machined surface of the two turning tool approach to zero. It can be seen as the residual stress disappears.

\section{Conclusion}

The innovative designed micro groove on the rake face of cemented carbide coating turning tool has an important effect on the radial distribution of residual stress of machined surfaces. The influence of the innovative micro groove on the residual stress can be concluded as: the micro groove can increase the thickness of the residual compressive stress layer and the maximum value of the residual compressive stress, and reduce the thickness of residual tensile stress layer and the maximum value of residual tensile stress of surface material of workpiece. Overall, the micro groove can improve the radial distribution of the residual stress of machined surface.

\section{Acknowledgement}

This work is financially supported by National Natural Science Foundation of China (51265005) and Doctoral Fund of Ministry of Education (20125201110001).

\section{References}

[1]Y.Z.Sun, H.T.Liu, Z.S. Lu, Finite element simulation and experimental research of residual stresses in the cutting based on the coupled thermo-mechanical model, Journal of Mechanical Engineering.47(2011):187-193.

[2] H.T. Liu, Z.S. Lu, Y.Z. Sun,Statue and development of residual stress on the surface in the cutting,Aviation Precision Manufacturing Technology.44(2008):17-19.

[3]S.G. Tian, L. Zhou, S.T. Huang, L.F. Xu, S.W. Liang, Influence of cutting parameters on titanium alloy fished surfaced residual stress, Tool Technology.44(2013):33-37.

[4] R.T. Peng, M. Liao, Y.Q. Tian, X.W. Liu, Experimental study on prestressed cutting of nickel-based superalloys, Journal of Mechanical Engineering.48(2012):186-191.

[5] Q. Wang, X.S. Liu, P. Wang, X.Xiong, H.Y. Fang,Numerical simulation of residual stress in 10Ni5VrMoV streel weldments, Journal of Materials Processing Technology.48(2017):77-86.

[6] B. Ahmad, M.F. Fitzpatrick, Minimization and mitigation of wire EDMcutting errors in the application of the contour method of residual stress measurement,Metallurgical and Materials transactions A-Physical Metallurgy and Materials Science.47(2016):301-313. 
[7]D.Nespor, B.Denkena, T. Grove, V.Boess,Differences and similarities between the induced residual stress after ball end milling and orthogonal cutting of Ti-6Al-4V,Journal of Materials Processing Technology.226(2015):15-24.

[8] A.Cellier,F.Chalon, P.V.Grimal, D.Bonhoure,R. Leroy,Effects of cutting angles in Ti-6al-4v milling process on surface integrity: influence of roughness and residual stresses on fatigue limit,Machining Science and Techmology.18(2014):565-584. 